\title{
O Ano de são José e a realidade do trabalho e das famílias na atualidade
}

The Year of Saint Joseph and the reality of work and families Nowadays

Oton da Silva Araújo Junior

Instituto Santo Tomás de Aquino - ISTA, Brasil

Robson Ribeiro de Oliveira Castro Chaves

Instituto Teológico Franciscano - ITF, Brasil

\section{Resumo}

0 texto se inspira em três comemorações, a saber: o Ano de São José (2020-2021), os 130 anos da Encíclica Rerum Novarum (1891) e os 5 anos da Exortação Apostólica Amoris Laetitia (2016) para refletir sobre a realidade do mundo do trabalho, tendo em vista a reforma trabalhista brasileira e a crescente tendência à informalidade, simbolizada pela uberização. Uma vez que o mercado de trabalho se vê abalado, a consequência imediata atingirá a vida familiar, muitas vezes rodeada novamente pelo fantasma da fome. Como tudo está interligado, como sugere Francisco, trabalho, família e segurança alimentar deverão ser o grande norte para a regulação econômica atual, chamada a promover vida em dignidade para todos e não o enriquecimento abusivo de uns, em detrimento da grande maioria sem os devidos acessos.

\section{Abstract}

The text is inspired by three commemorations, namely: the Year of Saint Joseph (2020-2021), the 130 years of the Encyclical Rerum Novarum (1891) and the 5 years of the Apostolic Exhortation Amoris Laetitia (2016) to reflect on the reality of world of work, in view of the Brazilian labor reform and the growing trend towards informality, symbolized by uberization. Once the job market is shaken, the immediate consequence will reach family life, often surrounded again by the specter of hunger. As everything is interconnected, as Francisco suggests, work, family and food security should be the great guide for the current economic regulation, called to promote life in dignity for all and not the abusive enrichment of some, to the detriment of the vast majority without dues hits.

\section{Palavras-chave}

São José.

Trabalho.

Família.

Uberização.

Papa Francisco.

\section{Keywords}

Saint Joseph. Work.

Family. Uberization. Pope Francis. 
“No ventre de Maria, Deus se fez homem. Mas, na oficina de José Deus também se fez classe”. (Pedro Casaldáliga)

\section{Introdução}

Ao nos determos sobre a figura de São José, somos chamados a refletir sobre duas condições básicas da vida, relacionadas ao mundo do trabalho e à vida familiar. Em muitas referências a José, vários papas o relacionaram ao homem trabalhador que ensinou o ofício ao filho e, com isso, garantia o sustento da família.

O que num primeiro momento pode parecer uma realidade cotidiana das famílias, assume em nossos dias um sinal de alerta devido à precarização do trabalho, com interferências diretas na vida familiar, ameaçada, inclusive, de cair nas garras da fome.

Na primeira parte, o presente artigo revisita algumas referências dos papas a respeito de São José ligadas ao mundo do trabalho para, em seguida, refletir sobre alguns desafios desse universo, agravados ainda mais pela pandemia.

Posteriormente, apresentaremos a realidade dos documentos e a questão de São José e dialogaremos com a realidade da pandemia e a Uberização e precarização do trabalho frente a uma realidade de comprometimentos das relações humanas.

\section{José, pai de família, homem trabalhador}

Por ocasião dos 150 anos da proclamação de São José como patrono da Igreja Universal, o papa Francisco convocou o Ano de São José (de 8 de dezembro de 2020 a 8 de dezembro de 2021), uma oportunidade para aprofundar nesse personagem tão importante e nem sempre devidamente 
463 | O Ano de são José e a realidade do trabalho e das famílias na atualidade

reconhecido, bem como buscar nele as inspirações necessárias para nosso tempo.

Dentre as características que primeiro saltam aos olhos a respeito de José está a de esposo e trabalhador, o que nessa oportunidade dará margem para refletirmos sobre família e trabalho (ou a ausência dele) em tempos tão turbulentos como os nossos.

A iconografia conservou a imagem de José e de seu Pequeno Filho aprendendo o ofício da carpintaria, numa cena bucólica e idealizada. No entanto, o mundo do trabalho nunca fora romântico, nem naqueles tempos nem nos atuais, e Francisco bem o sabe, como é possível ler na Carta Apostólica Patris Corde, por ocasião do $150^{\circ}$ aniversário da declaração de São José como padroeiro universal da Igreja:

Neste nosso tempo em que o trabalho parece ter voltado a constituir uma urgente questão social e o desemprego atinge por vezes níveis impressionantes, mesmo em países onde se experimentou durante várias décadas um certo bem-estar, é necessário tomar renovada consciência do significado do trabalho que dignifica e do qual o nosso Santo é patrono e exemplo ${ }^{1}$.

De igual modo, ao trabalho une-se a realidade familiar, em suas diversas constituições: “Uma família onde falte o trabalho está mais exposta a dificuldades, tensões, fraturas e até mesmo à desesperada e desesperadora tentação da dissolução"2. E Francisco aterrissa o discurso justamente lembrando-se da situação da pandemia: “A perda de trabalho que afeta tantos irmãos e irmãs e tem aumentado nos últimos meses devido à pandemia de Covid-19, deve ser um apelo a revermos as nossas prioridades"3. Façamos, pois, um breve percurso sobre alguns escritos papais a respeito de José e o mundo do trabalho.

\footnotetext{
${ }^{1}$ FRANCISCO. Carta Apostólica Patris Corde, por ocasião do $150^{\circ}$ aniversário da declaração de são José como padroeiro universal da Igreja, n. 02, 08 ago. 2020. Disponível em: https://www.vatican.va/content/francesco/pt/apost_letters/documents/papa-francescolettera-ap_20201208_patris-corde.html. Acesso em: 30 ago. 2021. (Daqui em diante = PC). ${ }^{2} \mathrm{PC}$, n. 6.

${ }^{3} \mathrm{PC}$, n. 6.
} 


\section{José e o mundo do trabalho nos documentos papais}

Em 2021, comemoramos, igualmente, os 130 anos da encíclica Rerum Novarum, um marco no diálogo da Igreja Católica com a sociedade moderna, sobretudo a respeito das novas realidades trabalhistas advindas da Revolução Industrial. Leão XIII, nesse escrito, referiu-se a José para dizer da dignidade do trabalho e a pobreza, não como um opróbrio, mas como um marco na humanidade, quando "O Filho de Deus e Deus mesmo, quis passar aos olhos do mundo por filho dum artesão; que chegou até a consumir uma grande parte da Sua vida em trabalho mercenário: 'Não é Ele o carpinteiro, o Filho de Maria?",4.

A Rerum Novarum (1981) se posiciona sobre as más condições de trabalho, a proteção do salário, as relações trabalhistas, e outros temas implicados nas novas relações do mundo moderno. Oito anos depois, o mesmo papa escreveu mais propriamente sobre São José na encíclica Quamquam Pluries (1889). O elogio a José relembra que fora ele quem promoveu o sustento de sua família com o trabalho. Numa visão fatalista da realidade, adverte:

José, contente do seu trabalho e do pouco que possuía, viveu com coragem e nobreza as angústias da vida, seguindo nisto o exemplo de Jesus, que embora sendo Senhor de tudo, fez-se servo de todos e não desdenhou abraçar voluntariamente a pobreza ${ }^{5}$.

Tudo isso porque há uma ordem natural à qual se deve obedecer, num pensamento típico da época. "Se é verdade que a justiça consente em poder libertar-se da pobreza e alcançar uma posição melhor, também é verdade que

\footnotetext{
${ }^{4}$ LEÃO XIII. Carta Encíclica Rerum Novarum sobre a condição dos operários, n. 13, 15 maio 1891. Disponível em: https://www.vatican.va/content/leoxiii/pt/encyclicals/documents/hf_l-xiii_enc_15051891_rerum-novarum.html. Acesso em: 4 ago. 2021.

5 LEÃO XIII. Carta Encíclica Quamquam Pluries sobre a devoção a São José, n. 4, tradução nossa, 15 ago. 1889. Disponível em: https://www.vatican.va/content/leoxiii/es/encyclicals/documents/hf_l-xiii_enc_15081889_quamquam-pluries.html. Acesso em: 4 ago. 2021. (Daqui em diante $=Q P$ ) 
a ninguém é permitido, nem à razão, nem à justiça, subverter a ordem estabelecida por Deus”6.

Cem anos depois, João Paulo II, em sua exortação apostólica Redemptoris Custos, também se dedicou a lembrar José como homem trabalhador.

Se a Família de Nazaré, na ordem da salvação e da santidade, é exemplo e modelo para as famílias humanas, é-o analogamente também o trabalho de Jesus ao lado de José carpinteiro [...]. 0 trabalho humano, em particular o trabalho manual, tem no Evangelho uma acentuação especial. E ainda: Graças ao seu banco de trabalho, junto do qual exercitava o próprio ofício juntamente com Jesus, José aproximou o trabalho humano do mistério da Redenção ${ }^{7}$.

A colaboração de José na Economia Divina se deu pela união a Maria, e com ela embrenhou-se numa aventura incerta por salvar mãe e filho, numa oficina concreta, com cheiro de madeira, com sons das serras e martelos, num ambiente de grande debilidade, no qual é José, mais uma vez, o exemplo.

A ele, ao seu coração, Deus confia coisas débeis: com efeito, uma promessa é débil, assim como é débil uma criança, mas também uma jovem sobre a qual ele teve uma suspeita. Debilidades que continuam também nos eventos sucessivos: Pensemos no nascimento do Menino, na fuga para o Egito. [E confessa Francisco]: gosto de pensar em José como o guardião das debilidades, inclusive das nossas debilidades. Com efeito, ele é capaz de fazer nascer muitas coisas bonitas das nossas debilidades, dos nossos pecados. Ele é guardião das debilidades para que se tornem firmes na fé.

Essa debilidade, para Francisco, não assume um caráter conformista, mas convoca ao cuidado, vocaciona a ser guarda, não só do ambiente familiar, mas de toda a criação. José nos inspira a sermos guardiães. Em José, "vemos

\footnotetext{
${ }^{6} \mathrm{QP}$, n. 5, tradução nossa.

7 JOÃO PAULO II. Exortação apostólica Redemptoris Custos sobre a figura e a missão de são José na vida de Cristo e da lgreja, n. 22, 15 ago. 1989. Disponível em: https://www.vatican.va/content/john-paul-ii/pt/apost_exhortations/documents/hf_jpii_exh_15081989_redemptoris-custos.html. Acesso em: 4 ago. 2021.

${ }^{8}$ FRANCISCO. José o sonhador. Meditações matutinas na Santa Missa celebrada na capela da casa Santa Marta. 20 mar. 2017.2 Disponível em: https://www.vatican.va/content/francesco/pt/cotidie/2017/documents/papa-francescocotidie_20170320_jose-o-sonhador.html. Acesso em: 4 ago. 2021.
} 
como se responde à vocação de Deus: com disponibilidade e prontidão; mas vemos também qual é o centro da vocação cristã: Cristo. Guardemos Cristo na nossa vida, para guardar os outros, para guardar a criação!"9.

Em sua homilia no início do pontificado, Francisco se inspira em José para conduzir a Igreja, tendo na mão o Anel do Pescador. Pastorear a Igreja, para Francisco,

É guardar as pessoas, cuidar carinhosamente de todas elas e cada uma, especialmente das crianças, dos idosos, daqueles que são mais frágeis e que muitas vezes estão na periferia do nosso coração. É cuidar uns dos outros na família: os esposos guardam-se reciprocamente, depois, como pais, cuidam dos filhos, e, com o passar do tempo, os próprios filhos tornam-se guardiões dos pais. É viver com sinceridade as amizades, que são um mútuo guardar-se na intimidade, no respeito e no bem. Fundamentalmente tudo está confiado à guarda do homem, e é uma responsabilidade que nos diz respeito a todos. Sede guardiões dos dons de Deus! ${ }^{10}$.

Naquela oportunidade, o papa Bergoglio dirigiu-se igualmente às autoridades econômicas, políticas e sociais, conclamando-as também a serem guardiães da criação: “não deixemos que sinais de destruição e morte acompanhem o caminho deste nosso mundo!"11 - disse o papa.

Tais realidades, no entanto, são incômodas ao atual modelo econômico, que privilegia mais o lucro adquirido por especulações financeiras do que em assegurar melhores condições de vida para a população, conforme nos apresenta o papa Francisco na Exortação Apostólica Evangelii Gaudium.

Quantas palavras se tornaram incômodas para este sistema! Incomoda que se fale de ética, incomoda que se fale de solidariedade mundial, incomoda que se fale de distribuição

\footnotetext{
${ }^{9}$ FRANCISCO. Santa Missa imposição do pálio e entrega do anel do pescador para o início do ministério petrino do bispo de Roma. Homilia do papa Francisco. 19 mar. 2013. Disponível em: https://www.vatican.va/content/francesco/pt/homilies/2013/documents/papafrancesco_20130319_omelia-inizio-pontificato.html. Acesso em: 4 ago. 2021.

${ }^{10}$ FRANCISCO. Santa Missa imposição do pálio e entrega do anel do pescador para o início do ministério petrino do bispo de Roma. Homilia do papa Francisco. 19 mar. 2013. Disponível em: https://www.vatican.va/content/francesco/pt/homilies/2013/documents/papafrancesco_20130319_omelia-inizio-pontificato.html. Acesso em: 4 ago. 2021.

${ }^{11}$ FRANCISCO. Santa Missa imposição do pálio e entrega do anel do pescador para o início do ministério petrino do bispo de Roma. Homilia do papa Francisco. 19 mar. 2013. Disponível em: https://www.vatican.va/content/francesco/pt/homilies/2013/documents/papafrancesco_20130319_omelia-inizio-pontificato.html. Acesso em: 4 ago. 2021.
} 
dos bens, incomoda que se fale de defender os postos de trabalho, incomoda que se fale da dignidade dos fracos, incomoda que se fale de um Deus que exige um compromisso em prol da justiça ${ }^{12}$.

E Francisco vincula o exercício de governo à garantia de postos de trabalhos: “É indispensável que os governantes e o poder financeiro levantem o olhar e alarguem as suas perspectivas, procurando que haja trabalho digno, instrução e cuidados sanitários para todos os cidadãos"13.

Francisco, ao considerar a realidade do trabalho a considera dentro da conjuntura econômica e política. Em sua encíclica sobre o Cuidado da Casa Comum, apresenta toda uma sessão sobre "A necessidade de defender o trabalho" ${ }^{14}$. Laudato Si relembra que

0 trabalho deveria ser o âmbito deste multiforme desenvolvimento pessoal, onde estão em jogo muitas dimensões da vida: a criatividade, a projeção do futuro, o desenvolvimento das capacidades, a exercitação dos valores, a comunicação com os outros, uma atitude de adoração ${ }^{15}$.

A orientação da economia - continua Francisco - "favoreceu um tipo de progresso tecnológico cuja finalidade é reduzir os custos de produção com base na diminuição dos postos de trabalho, que são substituídos por máquinas"16. E continua no mesmo parágrafo afirmando e citando Bento XVI ${ }^{17}$ :

A diminuição dos postos de trabalho tem também um impacto negativo no plano econômico com a progressiva corrosão do capital social, isto é, daquele conjunto de relações de

12 FRANCISCO. Exortação Apostólica Evangelii Gaudium sobre o anúncio do evangelho no mundo atual, $\mathrm{n}$ 203, 24 nov. 2013. Disponível em: https://www.vatican.va/content/francesco/pt/apost_exhortations/documents/papa-

francesco_esortazione-ap_20131124_evangelii-gaudium.html. Acesso em: 06 set. 2021. (Daqui em diante $=\mathrm{EG})$

${ }^{13}$ EG, n. 205.

${ }^{14}$ FRANCISCO. Carta encíclica Laudato Si sobre o cuidado da Casa Comum, ns. 124-129, 24 maio 2015.2 Disponível em: https: / /www.vatican.va/content/francesco/pt/encyclicals/documents/papa-

francesco_20150524_enciclica-laudato-si.html. Acesso em: 05 ago. 2021. (Daqui em diante = LS.)

${ }^{15}$ LS, n. 127.

${ }^{16}$ LS, n. 128.

${ }^{17}$ Maiores informações consultar: Carta encíclica Caritas in Veritate sobre o desenvolvimento humano integral na caridade $e$ na verdade. Disponível em: https://www.vatican.va/content/benedict-xvi/pt/encyclicals/documents/hf_benxvi_enc_20090629_caritas-in-veritate.html. Acesso em: 08 ago. 2021. n.32 
confiança, de credibilidade, de respeito das regras, indispensável em qualquer convivência civil ${ }^{18}$.

E vê elementos positivos na atividade empresarial, a qual

É uma nobre vocação orientada para produzir riqueza e melhorar o mundo para todos, pode ser uma maneira muito fecunda de promover a região onde instala os seus empreendimentos, sobretudo se pensa que a criação de postos de trabalho é parte imprescindível do seu serviço ao bem comum ${ }^{19}$.

Mais uma vez, o papa se direciona a são José que, com o seu trabalho e presença generosa, cuidou de Maria e de Jesus, defendeu-os e os livrou da violência dos injustos.

No Evangelho, [José] aparece descrito como um homem justo, trabalhador, forte; mas, da sua figura, emana também uma grande ternura, própria não de quem é fraco, mas de quem é verdadeiramente forte, atento à realidade para amar e servir humildemente. Por isso, foi declarado protetor da Igreja universal. Também Ele nos pode ensinar a cuidar, pode motivar-nos a trabalhar com generosidade e ternura para proteger este mundo que Deus nos confiou ${ }^{20}$.

Em 2021, há ainda uma terceira comemoração a qual queremos fazer memória: os cinco anos da Exortação apostólica pós-sinodal Amoris Laetitia sobre o amor na família. Os temas mais destacados dessa Exortação se fixaram no acolhimento aos casais de segunda união, o discernimento necessário no acompanhamento das famílias, e outros assuntos afins à realidade das famílias atuais.

Logo no primeiro capítulo, a Amoris Laetitia retoma o salmo 128 e reconhece na realidade familiar a importância do trabalho. "Comerás do fruto do teu próprio trabalho: assim serás feliz e viverás contente" (SI 128,2), num aceno claro ao livro de Gênesis. O capítulo faz uma rápida explanação sobre o trabalho no universo Bíblico, sobretudo no Antigo Testamento ${ }^{21}$.

\footnotetext{
${ }^{18}$ LS, n. 128.

${ }^{19}$ LS, n. 127.

${ }^{20}$ LS, n. 242.

${ }^{21}$ FRANCISCO. Exortação Apostólica pós-sinodal Amoris Laetitia sobre o amor na família sobre \begin{tabular}{l}
$o$ amor na família, cf. n. 24-26, 19 mar. 2016. Disponível em: \\
\hline Fronteiras, Recife, v. 4, n. 2, p. 461-482, jul./dez., 2021
\end{tabular}
} 
No capítulo seguinte, ao tratar da situação atual da família, Francisco refazendo-se à Relatio Finalis do Sínodo, assinala:

O atual sistema econômico produz várias formas de exclusão social. As famílias sofrem de modo particular com os problemas relativos ao trabalho. As possibilidades para os jovens são poucas e a oferta de trabalho é muito seletiva e precária. As jornadas de trabalho são longas e, muitas vezes, agravadas pelo tempo gasto no deslocamento. Isto não ajuda os esposos a encontrar-se entre si e com os filhos, para alimentar diariamente as suas relações ${ }^{22}$.

Francisco continua no mesmo tema da economia ao lembrar a situação das famílias caídas na miséria, penalizadas de tantas maneiras, nas quais as limitações da vida se fazem sentir de forma lancinante. Se todos têm dificuldades, estas, numa casa muito pobre, tornam-se mais duras ${ }^{23}$.

Num tom mais personalista, são lembradas as situações das mulheres que reivindicam seu lugar nos postos de trabalho ${ }^{24}$ e no pai que, por vezes, “está tão concentrado em si mesmo e no próprio trabalho ou então nas próprias realizações individuais que até se esquece da família” ${ }^{25}$, bem como as famílias monoparentais, as quais "são muitas vezes afligidas pela gravidade dos problemas econômicos, pela incerteza dum trabalho precário, pela dificuldade de manter os filhos, pela falta duma casa" ${ }^{26}$, e pontua ainda o ritmo frenético de vida, que chega a interferir na educação dos filhos ${ }^{27}$.

A pessoa de José, por sua vez, vem relacionada diretamente à educação de Jesus $^{28}$, bem como a todo o mistério do nascimento de Jesus, “no sim de Maria ao anúncio do anjo, quando foi concebida a Palavra no seu seio; e ainda no sim de José, que deu o nome a Jesus e cuidou de Maria; na festa dos pastores no presépio" 29 . Francisco faz questão de recordar que Jesus

https://www.vatican.va/content/francesco/pt/apost_exhortations/documents/papafrancesco_esortazione-ap_20160319_amoris-laetitia.html. Acesso em: 06 ago. 2021. (Daqui em diante $=\mathrm{AL}$ ).

${ }^{22} \mathrm{AL}, \mathrm{n} .44$.

${ }^{23}$ Cf. AL, n. 49.

${ }^{24}$ Cf. AL, n. 173.

${ }^{25} \mathrm{AL}, \mathrm{n} .176$.

${ }^{26}$ AL, n. 252.

${ }^{27}$ Cf. AL, n. 287.

${ }^{28}$ Cf. AL, n. 18.

${ }^{29} \mathrm{AL}, \mathrm{n} .65$. 
“não cresceu numa relação fechada e exclusiva com Maria e José, mas de bom grado movia-se na família alargada, onde encontrava os parentes e os amigos"30.

\section{O mundo do trabalho na Fratelli Tutti}

A encíclica sobre a fraternidade e a amizade social foi escrita durante a pandemia do novo Coronavírus e oficialmente assinada no túmulo de Francisco de Assis, o dia 03 de outubro de 2020. Nela, Francisco descreve um mundo fechado ao diálogo e aponta possíveis saídas à integração e ao respeito das diferenças entre povos e religiões. Dito isso, salta aos olhos as repetidas vezes em que o tema do trabalho aparece na encíclica. Aqui, nos restringiremos ao trabalho como remuneração, contrato trabalhista, enfim, uma vez que Francisco também utiliza a palavra como sinônimo de esforço, empenho, bem como de zelo pastoral.

Nosso primeiro aceno está no número 116, quando Francisco faz um elogio à solidariedade em suas diversas formas, dentre elas a de "lutar contra as causas estruturais da pobreza, a desigualdade, a falta de trabalho, a terra e a casa, a negação dos direitos sociais e laborais" ${ }^{31}$. A partir de uma ética global de solidariedade, tendo presente a dignidade humana, é que se torna possível desejar um planeta que garanta terra, teto e trabalho para todos. $\mathrm{E}$ continua Francisco: “Este é o verdadeiro caminho da paz, e não a estratégia insensata e míope de semear medo e desconfiança perante ameaças externas"32.

Um acento especial deve ser dado quando Francisco se dedica de maneira ainda mais precisa à questão do trabalho. Francisco inicia dizendo da importância da garantia do trabalho, como "possibilidade de fazer germinar

\footnotetext{
${ }^{30}$ AL, n. 182.

${ }^{31}$ FRANCISCO. Carta Encíclica Fratelli Tutti sobre a fraternidade e a amizade social, n. 116, 03 out. $2020 . \quad$ Disponível em: https://www.vatican.va/content/francesco/pt/encyclicals/documents/papafrancesco_20201003_enciclica-fratelli-tutti.html. Acesso em: 30 ago. 2021. (Daqui em diante $=\mathrm{FT})$.

32 FT, n.127. 
as sementes que Deus colocou em cada um"33. Dito isso, insiste: “ajudar os pobres com o dinheiro deve sempre ser um remédio provisório para enfrentar emergências. 0 verdadeiro objetivo deveria ser sempre consentir-lhes uma vida digna através do trabalho". E diz frontalmente: "não há pobreza pior do que aquela que priva do trabalho e da dignidade do trabalho" 34 .

E conclui o parágrafo dizendo:

Numa sociedade realmente desenvolvida, o trabalho é uma dimensão essencial da vida social, porque não é só um modo de ganhar o pão, mas também um meio para o crescimento pessoal, para estabelecer relações sadias, expressar-se a si próprio, partilhar dons, sentir-se corresponsável no desenvolvimento do mundo e, finalmente, viver como povo ${ }^{35}$.

Fratelli Tutti conclama os cristãos a se empenharem nas questões da sociedade, uma vez que "se a música do Evangelho cessar de repercutir nas nossas casas, nas nossas praças, nos postos de trabalho, na política e na economia, teremos extinguido a melodia que nos desafiava a lutar pela dignidade de todo o homem e mulher" ${ }^{36}$.

\section{A precarização do trabalho em meio a pandemia}

Atento ao clamor dos tempos, ao fazermos uma reflexão sobre o caminho de são José e sua função, seja na família seja no trabalho, é preciso observar a sua presença hoje e a construção de uma sociedade mais ética e justa. No exemplo de José, Jesus aprendeu o ofício de carpinteiro e também as tradições judaicas.

Jesus aprendeu a ser comprometido com a realidade da família e a zelar pelo trabalho. Teve acesso direto ao ofício de José e se comprometeu com toda a carpintaria: aprendeu a manipular as ferramentas certas para cada tipo de madeira ou serviço. Na carpintaria de José, compreendeu a sua

\footnotetext{
${ }^{33} \mathrm{FT}$, n. 162.

${ }^{34}$ FT, n. 162.

${ }^{35} \mathrm{FT}$, n. 162.

${ }^{36}$ FT, n. 277.
} 
missão, atento ao que via, transformava um pedaço torto de madeira em lindos objetos.

Vivemos uma sociedade preocupada com o consumo e o lucro. A vida, cujo valor era precarizado pelos idos da Revolução industrial, agora se torna algo descartável, sem ao menos valer os direitos inerentes a cada função.

Assim, conforme nos apresenta o papa Francisco, temos uma cultura de exploração de cada ser humano.

O ser humano é considerado, em si mesmo, como um bem de consumo que se pode usar e depois lançar fora. Assim teve início a cultura do "descartável", que aliás chega a ser promovida. Já não se trata simplesmente do fenômeno de exploração e opressão, mas de uma realidade nova: com a exclusão, fere-se, na própria raiz, a pertença à sociedade onde se vive, pois quem vive nas favelas, na periferia ou sem poder já não está nela, mas fora. Os excluídos não são "explorados", mas resíduos, "sobras"37.

Ao dialogarmos com a pessoa de José, homem que no silêncio e na condição de pai de Jesus compreendeu o seu projeto e aceitou os desígnios de Deus, encontramos urgência em refletir os problemas das famílias e o desemprego, a uberização e o descaso com as leis trabalhistas. Por isso, é urgente refletir que "o desemprego é o principal fator de exclusão social e assim se vai consolidando a cultura do descarte" ${ }^{38}$.

Com o avanço tecnológico e os desenvolvimentos das grandes empresas, há uma luta constante para o sustento das famílias. Um debate necessário para se falar do trabalho é a Uberização, termo cunhado para abarcar todos os tipos de serviços por aplicativos que existem que são, hoje, em sua ampla maioria, responsáveis pela locomoção de pessoas, entrega de alimentos, objetos e tudo que se possa imaginar.

A uberização obriga trabalhadores informais a escolher entre saúde e subsistência. Empregos sem qualquer proteção constitucional ou direitos. Hoje os precários são eles, amanhã talvez sejam todos. Outro grupo exposto à precariedade são os

\footnotetext{
${ }^{37}$ EG, n. 53.

38 GONZÁLES, Juan Biosca. A violação dos direitos humanos no trabalho. In.: ZACHARIAS, Ronaldo; MANZINI, Rosana. (org.). A doutrina social da igreja e o cuidado com os mais frágeis. São Paulo: Paulinas, 2018, p. 100.
} 
imigrantes e refugiados. Expostos à superexploração extrema, sem acesso à serviços públicos de saúde e privados de cidadania, são a imagem mais viva da precariedade laboral ${ }^{39}$.

Em uma entrevista ao site IHU Unisinos, o sociólogo Ricardo Antunes professor da Universidade Estadual de Campinas - apresenta a realidade dos trabalhadores como sendo a "uberização" do trabalho, e ele afirma na entrevista que "se homens e mulheres tiverem sorte hoje, o seu trabalho será precário" 40 .

Perante tal realidade, é preciso fazer ecoar o Compêndio da Doutrina Social da Igreja ${ }^{41}$ : “Defronte às modificações que se deram no mundo do trabalho, a solidariedade poderá ser recuperada e quiçá melhor fundada em relação ao passado se houver um empenho para uma redescoberta do valor subjetivo do trabalho". ${ }^{42}$ Assim, é preciso compreender que a Doutrina Social da Igreja dá “ à pessoa e, em especial, aos grupos mais fragilizados e vulneráveis, o lugar central no processo de desenvolvimento social"43.

O capitalismo, como já é tema de estudos há vários anos, se tornou a arquitrave da sociedade. Dito isso, nos perguntamos: porque, mesmo diante de tantos problemas, o capitalismo ainda impera e é algo que é enaltecido pelas classes trabalhadoras? A resposta não é simples, mas tem a sua realidade pautada na construção de um pensamento no qual o empregado está usufruindo do lucro da empresa ao ser seu funcionário, o que se revela grande ilusão.

Entender o que se passa hoje com o ser humano e sua relação do trabalho nos mostra que, diante da realidade capitalista, o trabalho se tornou

\footnotetext{
39 GASDA, Élio. Trabalho: o futuro no presente. Dom Total. 11 jun. 2020. Disponível em: https://domtotal.com/noticia/1451696/2020/06/trabalho-o-futuro-no-presente/. Acesso em: 4 ago. 2021.

${ }^{40}$ IHU UNISINOS. "Uberização" do trabalho: caminhamos para a servidão, e isso ainda será um privilégio. Entrevista com Ricardo Antunes. Disponível em: http://www.ihu.unisinos.br/78noticias/591102-uberizacao-nos-leva-para-a-servidao-diz-pesquisador. Acesso em: 4 ago. 2021.

${ }^{41}$ Daqui em diante $=$ CDSI.

42 PONTIFÍCIO CONSELHO “JUSTIÇA E PAZ”. Compêndio da Doutrina Social da Igreja, n. 308. Disponível em: https://www.vatican.va/roman_curia/pontifical_councils/justpeace/documents/rc_pc_justp eace_doc_20060526_compendio-dott-soc_po.html. Acesso em: 8 ago. 2021. (Daqui em diante $=$ CDSI).

${ }^{43}$ MANZINI, 2018, p. 36.
} 
apenas um produto para a produção de riqueza, não para o empregado, mas para o empregador.

Há, cada vez mais, uma globalização individualista, a partir da qual se procura apenas 0 interesse pessoal que degrada a relação humana, gerando a escravização e a desonestidade. A ganância e o desejo por poder e enriquecimento, juntamente com a desvalorização do ser humano e de sua dignidade, são atributos cada vez mais cultuados hoje ${ }^{44}$.

Sendo assim, ocorre a falsa imagem de que o trabalhador faz parte do processo, quando na verdade é apenas uma peça da engrenagem que, quando emperra por algum defeito, esta peça é substituída por outra.

Jesus tem posições claras a respeito do trabalho e da desvalorização dos indivíduos:

Jesus ensina aos homens a não se deixarem escravizar pelo trabalho. [...] O trabalho não deve afligir (cf. Mt 6, 25.31.34): preocupado e agitado por muitas coisas, o homem corre o risco de negligenciar o Reino de Deus e a Sua justiça (cf. Mt 6, 33), de que verdadeiramente necessita; tudo mais, inclusive o trabalho, encontra o seu lugar, o seu sentido e o seu valor somente se orientado para esta única coisa necessária, que jamais the será tirada (cf. Lc 10, 40-42) ${ }^{45}$.

Destarte, Ricardo Antunes apresenta o panorama global de formação da nova classe trabalhadora na era digital, denominada por ele como “proletariado de serviços” em seu livro “O privilégio da servidão: o novo proletariado de serviços na era digital" 46 .

De fato, pensar nessa realidade é constatar que o indivíduo perdeu todos os seus direitos, duramente conquistados.

Os direitos desaparecem, porque se desvanece a figura do trabalhador ou da trabalhadora, e se faz aflorar a falsa ideia de um empreendedor, de um PJ, de um trabalhador que é dono do seu instrumental de trabalho, e isso faz com que a

${ }^{44}$ CHAVES, Robson Ribeiro de Oliveira Castro. Terra, teto e trabalho: Direitos Humanos e a Doutrina Social da Igreja a partir do Papa Francisco. Revista Encontros Teológicos, Florianópolis, v. 36, n.1, Jan.-Abr. 2021, p. 175.

${ }^{45}$ CDSI, n. 260.

${ }^{46}$ ANTUNES, Ricardo. O privilégio da servidão: o novo proletariado de serviços na era digital. São Paulo: Boitempo, 2018. 
degradação da vida no trabalho no capitalismo do nosso tempo chegue a um patamar que se assemelha, em plena era informacional-digital, à era da revolução industrial ${ }^{47}$.

A reforma trabalhista atual dá a falsa impressão e um diálogo entre patrões e empregados, fazendo com que os trabalhadores pensem que estão em padrão de igualdade com seus empregadores.

Nesse contexto, é urgente observar que, com as novas tecnologias e o avanço de diversos aplicativos e conceitos de trabalho, hoje, mediante a realidade, temos uma classe trabalhadora fragmentada, desestruturada e individual, pois luta por seus direitos ao mesmo tempo em que conduz seu próprio carro por mais de 12 horas, fazendo inúmeras viagens ou pedala o dia todo fazendo entregas por toda a cidade, sendo assim o "futuro do trabalho não está unicamente nas mãos dos grandes dirigentes, das grandes potências e dos super-ricos. Está fundamentalmente nas mãos dos povos" ${ }^{\text {. }}$.

Toda essa construção de um novo proletariado - um proletariado digital - transforma a sociedade e faz dos trabalhadores objetos que, quando não servem ou apresentam “defeito”, são desprezados. Ricardo Antunes apresenta a seguinte afirmação:

Quando a atividade humana se resume exclusivamente ao trabalho - como muitas vezes ocorre no mundo capitalista e em sua sociedade do trabalho abstrato -, ela se converte em um mundo penoso, alienante, aprisionado e unilateralizado. É aqui que emerge uma constatação central: se por um lado necessitamos do trabalho humano e de seu potencial emancipador e transformador, por outro devemos recusar o trabalho que explora, aliena e infelicita o ser social, tal como o conhecemos como sob a vigência e o comando do trabalho abstrato" ${ }^{49}$.

Um aspecto importante é a construção moral do indivíduo que, desde a juventude, vem sendo comprometida, principalmente com a precarização do trabalho. Para a juventude, "o subemprego - o trabalho desqualificado -

\footnotetext{
${ }^{47}$ IHU UNISINOS. "Uberização" do trabalho: caminhamos para a servidão, e isso ainda será um privilégio. Entrevista com Ricardo Antunes. Disponível em: http://www.ihu.unisinos.br/78noticias/591102-uberizacao-nos-leva-para-a-servidao-diz-pesquisador. Acesso em: 4 ago. 2021. ${ }^{48}$ GASDA, 2020.

${ }^{49}$ ANTUNES, 2018, p. 26, grifo do autor.
} 
nada lhe ensina e garante: de maneira contraditória, o lança a um profundo processo de alienação, desconhecendo suas potencialidades e o sentido primeiro de suas atividades"

Por isso, diante dessa construção social, muitos brasileiros e brasileiras perderam seus empregos ou tiveram que adaptar a vida para completar a renda de uma família numerosa e que vive, muitas das vezes, nas periferias, não somente físicas, mas também existenciais, como já nos alertava o Papa Francisco.

A Igreja "em saída" é uma Igreja com as portas abertas. Sair em direção aos outros para chegar às periferias humanas não significa correr pelo mundo sem direção nem sentido. Muitas vezes é melhor diminuir o ritmo, pôr de parte a ansiedade para olhar nos olhos e escutar, ou renunciar às urgências para acompanhar quem ficou caído à beira do caminho. Às vezes, é como o pai do filho pródigo, que continua com as portas abertas para, quando este voltar, poder entrar sem dificuldade (EG, n. 46).

Assim, é necessário compreender a relação existente entre os empregadores e empregados; é preciso ter como foco a resolução de problemas atuais e a realidade frente aos desafios da atualidade. Para tentar reverter esse quadro, muitos trabalhadores se sujeitam à exploração para manter seus empregos. A pandemia colocou o ser humano em uma realidade complexa e difícil. A crise do trabalho é resultado de uma opção social que mostrou a sua pior face: a fome!

Segundo a FAO, Organização das Nações Unidas para a Agricultura e Alimentação, 55,2\% dos lares brasileiros enfrentavam algum nível de insegurança alimentar, ou seja, cerca de 116 milhões de brasileiros. Deste número, 19 milhões enfrentam a fome diariamente, em situação catastrófica. Porém, ao lado desta realidade, temos a previsão de que em 2021 a produção

\footnotetext{
${ }^{50}$ OLIVEIRA, Adelino Francisco de. Juventude e violação de direitos fundamentais. Reflexões à luz da Doutrina Social da Igreja e dos direitos humanos. In.: ZACHARIAS, Ronaldo; MAZINI, Rosana (org.). A doutrina social da igreja e o cuidado com os mais frágeis. São Paulo: Paulinas, 2018, p. 84.
} 
de grãos, cereais e leguminosas deve bater recorde de 258,5 milhões de toneladas $^{51}$.

Vivenciar essa realidade pandêmica é um desafio para homens e mulheres que, mesmo diante dos problemas atuais, buscam olhar a realidade com esperança e se esforçam para trabalhar dignamente se preocupando, cada vez mais com a família e todos que dependem de seus esforços. Diante desse contexto e período, os mais pobres precisaram se reinventar em suas atitudes e um novo jeito de ser e viver, infelizmente comprometendo a vida e a construção e suas relações.

Dessa maneira, a dignidade da pessoa humana é fator determinante para o crescimento e desenvolvimento de suas funções sociais, dentre elas, o trabalho. Assim "É a dignidade da pessoa que constitui o ponto focal de toda a reflexão sobre a eticidade da convivência. A dignidade da pessoa precede e fundamenta os seus direitos. É ela que deve estar no centro de toda ética econômica e política" ${ }^{2}$.

Importante reforçar a dignidade do trabalhador e do trabalho, diante de uma crise do nosso tempo que é “econômica, social, cultural e espiritual, pode constituir para todos um apelo a redescobrir o valor, a importância e a necessidade do trabalho para dar origem a uma nova 'normalidade', em que ninguém seja excluído" 53 .

Desse modo, Francisco se dedica a falar sobre o trabalho, as famílias e a crise que vivemos em tempos de pandemia. Assim, sua preocupação é constante na realidade que precisa ser revista, é necessário um mundo mais humano, autêntico e comprometido com todos.

De fato, é necessário observar que a realidade do trabalho hoje está desfigurada; infelizmente temos a grande necessidade de falar sobre direitos para o crescimento do ser humano.

Para o jovem pobre, morador de regiões periféricas, marcadas pela precariedade estrutural, em áreas sem condições básicas de saneamento,

${ }^{51}$ Cf. UOL ECONOMIA. 08 jul. 2021. IBGE prevê safra recorde de 258,5 milhões de toneladas em 2021. Disponível em: https://economia.uol.com.br/noticias/agenciabrasil/2021/07/08/safra-recorde-de-2585-milhoes-de-toneladas-em-2021.htm>. Acesso em: 10 set. 2021.

${ }^{52}$ MANZINI, 2018, p. 32-33.

${ }^{53}$ PC, n. 6. 
educação, saúde, habitação etc., os direitos humanos, a violação de tais direitos acontece diuturnamente, tomando o cotidiano da existência ${ }^{54}$.

De fato, a perda de direitos é algo que já corre a longo prazo no cotidiano de tantos homens e mulheres que perdem seus direitos.

A desumanização do trabalho é a dimensão mais selvagem da economia. Desintegra a sociedade: explosão do desemprego, precariedade laboral, destruição ambiental, misoginia, xenofobia, racismo, destruição da saúde e da educação. A pandemia escancarou a brutalidade das desigualdades de classe, raça e sexo. A dimensão da brutal concentração da riqueza foi agravada pela pandemia ${ }^{55}$.

E sua crítica apresenta a realidade das classes trabalhadoras mais pobres que sofrem com a pandemia e seus riscos. É preciso compreender o que significa o distanciamento social das classes e o grande compromisso com os mais vulneráveis.

Em consonância nessa realidade, a juventude sofre com problemas e os aspectos da desumanização: “O trabalho precarizado, sem garantias, não lhe permite [o jovem] a possiblidade de crescimento e humanização"56. A condição humana é de se relacionar com todos e todas. Pautada em uma relação mais humana e comprometida deve atrelar ao discurso de igualdade a construção de uma realidade de transformação para todos e todas.

A nossa conduta ético-moral se faz refletir sobre os princípios, pois diante do outro e da sua agonia, devemos considerar como nossa também a sua dor e o seu sofrimento. Uma conduta moral duvidosa, sem apreço pela vida, nos leva a deixar de vivenciar os melhores momentos de nossas vidas.

\section{Considerações finais}

Se a atual economia de mercado trouxe a sensação de bem-estar, acessos ilimitados, capacidades de usufruir das benesses modernas apenas

\footnotetext{
${ }^{54}$ OLIVEIRA, Adelino Francisco de. Juventude e violação de direitos fundamentais. Reflexões à luz da Doutrina Social da Igreja e dos direitos humanos. In: ZACHARIAS, Ronaldo; MAZINI, Rosana (org.). A doutrina social da igreja e o cuidado com os mais frágeis. São Paulo: Paulinas, 2018, p. 85.

${ }^{55}$ GASDA, 2020.

${ }^{56}$ OLIVEIRA, 2018, p. 84.
}

Fronteiras, Recife, v. 4, n. 2, p. 461-482, jul./dez., 2021 
pelo clique no celular, ao mesmo tempo devemos considerar que a relação trabalho e emprego não é propriamente a primeira prioridade da pauta econômica atual. Os interesses se veem mais voltados à lucratividade das empresas, ao rendimento maior dos investidores, do que propriamente considerar as pessoas envolvidas nos processos produtivos.

Voltar à pessoa de São José nos faz recordar justamente essas duas dimensões, tão fundamentais na vida: o trabalho e a família. Se as novas tecnologias possibilitam outras formas de trabalho, também é verdade que a insegurança trabalhista aumentou na mesma proporção. A substituição das pessoas, os contratos trabalhistas feitos sem a devida atenção aos direitos dos trabalhadores, e tantos outros fatores têm-nos feito vivenciar uma instabilidade enorme, em vários seguimentos sociais. Em tempos de pandemia, a situação se agravou ainda mais, dado o fechamento do comércio, a alteração na oferta de bens e serviços, na incapacidade de muitos em se adequarem às “novas exigências do mercado".

Pensar numa economia “que faz viver e não mata, inclui e não exclui, humaniza e não desumaniza, cuida da criação e não a devasta" ${ }^{57}$ é um dos grandes desafios de nosso tempo.

José, o carpinteiro de Nazaré, continua sendo um modelo inspirador para os tempos atuais. Em sua oficina, educou o próprio Filho de Deus, ao lado de sua Jovem Esposa. Ali, com o suor do rosto e os calos nas mãos, pôde entender o valor imenso da família e o trabalho.

\section{Referências}

ANTUNES, Ricardo. O privilégio da servidão: o novo proletariado de serviços na era digital. São Paulo: Boitempo, 2018.

CHAVES, Robson Ribeiro de Oliveira Castro. Terra, teto e trabalho: Direitos Humanos e a Doutrina Social da Igreja a partir do Papa Francisco. Revista Encontros Teológicos, Florianópolis. V.36, n.1, Jan.-Abr. 2021, p. 173-189.

${ }^{57}$ FRANCISCO. Carta para o evento "Economy of Francesco". 01 maio 2019. Disponível em: https://www.vatican.va/content/francesco/pt/cotidie/2017/documents/papa-francescocotidie_20170320_jose-o-sonhador.html. Acesso em: 4 ago. 2021. 
FRANCISCO. Santa Missa imposição do pálio e entrega do anel do pescador para o início do ministério petrino do bispo de Roma. Homilia do papa Francisco. 19 mar. 2013. Disponível em:

https://www.vatican.va/content/francesco/pt/homilies/2013/documents/pa pa-francesco_20130319_omelia-inizio-pontificato.html. Acesso em: 4 ago. 2021.

FRANCISCO. Exortação Apostólica Evangelii Gaudium, sobre o anúncio do evangelho no mundo atual. 24 nov. 2013. Disponível em:

https://www.vatican.va/content/francesco/pt/apost_exhortations/document s/papa-francesco_esortazione-ap_20131124_evangelii-gaudium.html. Acesso em: 06 set. 2021.

FRANCISCO. Carta encíclica Laudato Si sobre o cuidado da Casa Comum. 24 maio 2015. Disponível em:

https://www.vatican.va/content/francesco/pt/encyclicals/documents/papafrancesco_20150524_enciclica-laudato-si.html. Acesso em: 05 ago. 2021.

FRANCISCO. Exortação Apostólica pós-sinodal Amoris Laetitia sobre o amor na família, sobre o amor na família. 19 mar. 2016. Disponível em:

https://www.vatican.va/content/francesco/pt/apost_exhortations/document s/papa-francesco_esortazione-ap_20160319_amoris-laetitia.html. Acesso em: 06 ago. 2021.

FRANCISCO, José o sonhador. Meditações matutinas na Santa Missa celebrada na capela da casa Santa Marta. 20 mar. 2017. Disponível em:

https://www.vatican.va/content/francesco/pt/cotidie/2017/documents/pap a-francesco-cotidie_20170320_jose-o-sonhador.html. Acesso em: 4 ago. 2021.

FRANCISCO. Carta para o evento "Economy of Francesco". 01 maio 2019. Disponível em:

https://www.vatican.va/content/francesco/pt/cotidie/2017/documents/pap a-francesco-cotidie_20170320_jose-o-sonhador.html. Acesso em: 4 ago. 2021.

FRANCISCO. Carta Apostólica Patris Corde, por ocasião do $150^{\circ}$ aniversário da declaração de são José como padroeiro universal da Igreja. 08 ago. 2020. Disponível em:

https://www.vatican.va/content/francesco/pt/apost_letters/documents/pap a-francesco-lettera-ap_20201208_patris-corde.html. Acesso em: 30 ago. 2021.

FRANCISCO. Carta Encíclica Fratelli Tutti sobre a fraternidade e a amizade social. 03 out. 2020. Disponível em: 
https://www.vatican.va/content/francesco/pt/encyclicals/documents/papafrancesco_20201003_enciclica-fratelli-tutti.html. Acesso em: 30 ago. 2021.

GASDA, Élio. Trabalho: o futuro no presente. Dom Total. 11 jun. 2020. Disponível em: https://domtotal.com/noticia/1451696/2020/06/trabalho-ofuturo-no-presente/. Acesso em: 4 ago. 2021.

GONZÁLES, Juan Biosca. A violação dos direitos humanos no trabalho. In.: ZACHARIAS, Ronaldo; MAZINI, Rosana. (org.). A doutrina social da igreja e o cuidado com os mais frágeis. São Paulo: Paulinas, 2018, p. 91-116.

IHU UNISINOS. "Uberização" do trabalho: caminhamos para a servidão, e isso ainda será um privilégio. Entrevista com Ricardo Antunes. Disponível em: http: / / www.ihu.unisinos.br/78-noticias/591102-uberizacao-nos-leva-para-aservidao-diz-pesquisador. Acesso em: 4 ago. 2021.

JOÃO PAULO II, Exortação apostólica Redemptoris Custos, sobre a figura e a missão de são José na vida de Cristo e da Igreja. 15 ago. 1989. Disponível em: https://www.vatican.va/content/john-paul-

ii/pt/apost_exhortations/documents/hf_jp-ii_exh_15081989_redemptoriscustos.html. Acesso em: 4 ago. 2021.

LEÃO XIII, Carta Encíclica Rerum Novarum sobre a condição dos operários. 15 maio 1891. Disponível em: https://www.vatican.va/content/leoxiii/pt/encyclicals/documents/hf_l-xiii_enc_15051891_rerum-novarum.html. Acesso em: 4 ago. 2021.

LEÃO XIII, Carta Encíclica Quamquam Pluries sobre a devoção a São José. 15 ago. 1889. Disponível em: https://www.vatican.va/content/leoxiii/es/encyclicals/documents/hf_l-xiii_enc_15081889_quamquampluries.html. Acesso em: 4 ago. 2021.

OLIVEIRA, Adelino Francisco de. Juventude e violação de direitos fundamentais. Reflexões à luz da Doutrina Social da Igreja e dos direitos humanos. In: ZACHARIAS, Ronaldo; MAZINI, Rosana (org.). A doutrina social da igreja e o cuidado com os mais frágeis. São Paulo: Paulinas, 2018, p. 69-90.

PONTIFÍCIO CONSELHO “JUSTIÇA E PAZ”. Compêndio da Doutrina Social da Igreja. Disponível em:

https://www.vatican.va/roman_curia/pontifical_councils/justpeace/docume nts/rc_pc_justpeace_doc_20060526_compendio-dott-soc_po.html. Acesso em: 8 ago. 2021. 
UOL ECONOMIA. IBGE prevê safra recorde de 258,5 milhões de toneladas em 2021. 08 jul. 2021. Disponível em:

https: / /economia.uol.com.br/noticias/agencia-brasil/2021/07/08/safrarecorde-de-2585-milhoes-de-toneladas-em-2021.html. Acesso em: 10 set. 2021.

Trabalho submetido em 20/08/2021.

Aceito em 01/12/2021.

Oton da Silva Araújo Junior

Doutor em Teologia Moral pela Pontifícia Universidade Lateranense - Roma. Professor do Instituto Santo Tomás de Aquino e da Faculdade Jesuíta de Filosofia e Teologia, ambos em Belo Horizonte, Minas Gerais. E-mail: freioton@gmail.com

Robson Ribeiro de Oliveira Castro Chaves

Mestre em Teologia Moral pela Faculdade Jesuíta de Filosofia e Teologia em Belo Horizonte. Professor de Teologia Moral do Instituto Teológico Franciscano (ITF), em Petrópolis, Rio de Janeiro. E-mail: robsonrcastro@yahoo.com.br 